\title{
NARRATIVAS DE PROFESSORES E PROCESSOS DE FORMAÇÃO: CUIABÁ (MT) E SÃO GONÇALO (RJ) EM DIÁLOGO
}

\section{FILOMENA MARIA DE ARRUDA MONTEIRO}

Universidade Federal de Mato Grosso

HELENA AMARAL DA FONTOURA

Universidade do Estado do Rio de Janeiro

RESUMO Este texto se estrutura a partir de investigações envolvendo dois projetos de pesquisa, realizados em instituições distintas, que dialogam e se complementam. Tais estudos objetivam apresentar contribuições compartilhadas sobre dimensões vinculadas às práticas e aos processos de formação docente e de pesquisa narrativa desenvolvida em contextos específicos, com interlocução entre metodologias. Destacamos, a partir dos achados de nossas pesquisas, contribuições para um processo de formação emancipatória, apostando no fortalecimento do professor, seus saberes e suas práticas, como aspecto fundamental que contribui para uma inserção docente, crítica e criativa, abrindo outras possibilidades de experiência na escola e na sociedade. Especificamente, chama-se a atenção aqui para a questão relacional, tanto na pesquisa narrativa quanto no entendimento da formação docente como processo de aprendizagem de estratégias e capacidades para aprender com os outros, a partir dos outros e para os outros, pois, quando a profissão docente é respeitada e os professores apoiados em sua aprendizagem profissional, é mais provável que ocorra uma melhoria na qualidade dos processos educativos para professores e alunos.

Palavras-chave: Formação de Professores. Narrativas. Desenvolvimento profissional docente.

ABSTRACT NARRATIVES OF TEACHERS

\section{AND FORMATION PROCESSES: CUIABÁ (MT) AND SÃO GONÇALO (RJ) IN DIALOGUE}

This text is structured from investigations involving two research projects in different institutions that dialogue and comple- 
ment each other. These studies aim to introduce shared contributions on linked dimensions to the practices and processes of teacher formation and narrative research developed in specific contexts, with dialogue between methodologies. We highlight, from the findings of our researches, contributions to an emancipatory process, focusing on strengthening teachers, their knowledge and their practices, as a fundamental aspect that contributes to a critical and creative insertion, opening up other possibilities of experience in school and society. Specifically, we draw attention here to the issue in both the relational narrative research and understanding of teacher formation as a process of learning strategies and skills to learn from others, from the other or others, because when the teaching profession is respected and teachers are supported in their professional learning, is more likely to occur an improvement in the quality of educational processes for teachers and students.

Keywords: Teachers Formation. Narratives. Teacher professional development.

\section{RESUMEN RELATOS DE DOCENTES Y PROCESOS DE FORMACIÓN: CUIABÁ (MT) Y SÃO GONÇALO (RJ) EN DIÁLOGO}

Este texto está estructurado en indagaciones de dos proyectos de investigación en diferentes instituciones, en diálogo y complementarios. Estos estudios pretenden introducir contribuciones compartidas en dimensiones vinculadas a los procesos de formación docente y de investigación narrativa desarrollada en contextos específicos, con interlocución entre metodologías. Destacamos de los resultados, las contribuciones a un proceso emancipador, centrado en el fortalecimiento del profesor, sus conocimientos y sus prácticas como un aspecto fundamental que contribuye a una inserción crítica y creativa, abriendo otras posibilidades de experiencia en la escuela y en la sociedad. Específicamente, se llama la atención sobre la cuestión relacional, tanto en la investigación narrativa como en el entendimiento de la formaçión docente como proceso de aprendizaje de estrategias y capacidades para aprender con los otros, a partir de los otros y para los otros, pues cuando la profesión docente es respectada y los profesores apoyados en su aprendizaje profesional es más probable que ocurra una mejoría en la calidad de los procesos educativos para profesores e alumnos.

Palabras clave: Formación de los docentes. Narrativas. Desarrollo profesional docente. 


\section{Introdução}

Formar professores, em uma sociedade desigual, como a brasileira, é sempre um desafio, principalmente para os cursos de Pedagogia de universidades públicas, que enfrentam muitos obstáculos, desde questões de infraestrutura básica até estereótipos relacionados à escolha do magistério como uma carreira de segunda linha. Em nossas pesquisas, falamos de contextos em que os cursos de formação acontecem em uma universidade federal da região centro-oeste e em um campus de periferia de uma universidade estadual da região sudeste. Espaços formativos que se revelam com possibilidades e dificuldades, expressas nas mais diferentes formas, desde entraves materiais a desesperanças de formadores e de docentes em formação, atravessadas por esperanças, enamoramentos pela profissão e inúmeras contradições.

Posto o enorme desafio de se fazer formação docente no país, trazemos neste texto a contribuição de dois projetos de pesquisa desenvolvidos pelas autoras que, postos em diálogo, buscam ressignificar o tema em tela.

\section{Sobre a formação de professores}

Gatti (2009; 2010; 2014) desenvolveu estudos que têm apontado diferentes perspectivas e possibilidades da formação docente, ressaltando a importância de investigações que levem à compreensão, de forma mais aprofundada, de propostas de formação de professores. Tais estudos apontam também para perspectivas positivas e experiências de sucesso, construídas a partir de propostas formativas diversas, em contextos também diversos, mas que podem apresentar pistas para se pensar a formação de professores, em diferentes realidades. Por outro lado, refletem sobre problemas e fragilidades, comuns aos diversos programas de formação, que acabam por dificultar um processo formativo inicial de maior qualidade. A autora identifica oito pontos que considera interferirem na qualidade da formação dos professores e em suas atuações profissionais nos contextos das escolas: a) a ausência de uma perspectiva de contexto social e cultural e do sentido social dos conhecimentos; b) a ausência, nos cursos de licenciatura, e entre seus docentes formadores, de um perfil profissional claro de professor enquanto profissional (em muitos casos será preciso criar, nos que atuam nesses cursos de formação, a consciência de que se está formando um professor); c) a falta de integração das áreas de conteúdo e das disciplinas pedagógicas, dentro de cada área e entre si; d) a escolha de conteúdos curriculares; e) a formação dos formadores; f) a falta de uma carreira suficientemente atrativa e de condições de trabalho; $g$ ) a ausência de módulo escolar com certa durabilidade, em termos de professores e funcionários; e h) a precariedade quanto a insumos para o trabalho docente (GATTI, 2009).

Para Estrela (2001), a docência constitui uma profissão, atividade remunerada e socialmente reconhecida, que se reveste de um conjunto articulado de saberes, saberes-fazeres e atividades. A autora reitera a importância de uma formação profissional longa e certificada, premissa com a qual compactuamos. Trabalha, ainda, com a ideia de que a formação de professores, sobretudo a formação inicial, deve proporcionar experiências de articulação dialética entre teoria e prática, de modo a neutralizar o perigo de uma atuação profissional pautada em uma imitação acrítica de modelos de ação pedagógica, comumente oferecidos pelos programas de formação aos futuros professores.

$\mathrm{Na}$ literatura sobre o tema formação, temos encontrado formulações sobre o conceito de desenvolvimento profissional docente, em substituição ao de formação inicial e/ou 
continuada, em alguns autores, como Imbernón (2006), Marcelo Garcia (1999; 1995) e Nóvoa (2008; 2002; 1995), entre outros. A preferência por essa conceituação é justificada por Marcelo Garcia (1999), porque define, claramente, a concepção de profissional do ensino; e o termo desenvolvimento profissional sugere evolução e continuidade, rompendo com a tradicional justaposição entre formação inicial e continuada. Assim, o desenvolvimento profissional docente é entendido como um processo, que pode ser individual e/ou coletivo, mas que preferivelmente se contextualiza no local de trabalho do docente - a escola -, e que contribui para o desenvolvimento das competências profissionais por meio de experiências de diferentes características, tanto formais como informais. Esta abordagem apresenta uma forma de implicação e de resolução de problemas escolares, a partir de uma perspectiva que supera a característica tradicionalmente individualista das atividades de aperfeiçoamento dos professores (MARCELO GARCIA, 1995).

Nessa perspectiva, a escola é o espaço onde as reflexões individuais, na prática e sobre a prática, são discutidas e partilhadas, permitindo o desenvolvimento de processos colaborativos e coletivos de investigação-ação, em que os indivíduos podem transformar suas aprendizagens em intervenções que as incorporem. Salienta-se a organização da formação orientada para o desenvolvimento profissional, o que implica a consideração das necessidades individuais e coletivas, pessoais e profissionais, dos docentes e dos contextos em que trabalham, bem como a fase da carreira em que se encontram. Gatti e Barreto (2009) afirmam que a formação continuada vista como desenvolvimento profissional é a base de dois modelos defendidos na literatura educacional: as oficinas de reflexão sobre a prática e a formação centrada no fortalecimento institucional. Sobre o primeiro modelo, destacam o alto valor formativo e seus relevantes efeitos; por outro lado, limitado, já que atinge apenas as dimensões da unidade escolar em que se desenvolve, não respondendo a necessidades sistêmicas.

Tomamos como referencial de formação, então, a concepção de desenvolvimento profissional, para discutir os processos e contextos de desenvolvimento e aprendizagem da docência, partindo do princípio de que a formação de professores integra os processos de desenvolvimento profissional como um contínuo que se constrói, de forma dinâmica e complexa, ao longo de toda a trajetória pessoal e profissional dos professores, a partir da influência dos múltiplos contextos e lugares nos quais se envolvem estes professores, em suas trajetórias formativas e de atuação profissional (MARCELO GARCIA, 1995; 1999; NÓVOA, 1995; 2002; 2008; DAY, 2001; 2005; IMBERNÓN, 2006).

\section{Sobre narrativas}

Para Clandinin e Connelly (2011), experiência vivida, como fonte de conhecimento, é o objeto de estudo das narrativas. Esses autores chamam de história ou relato ao fenômeno, e de narrativa à pesquisa, enfatizando que a vida é preenchida de fragmentos narrativos compondo o todo de uma experiência vivida, em diferentes momentos históricos, tempos e espaços. Nessa perspectiva, para esses autores, a pesquisa narrativa é composta por três dimensões: temporalidade, sociabilidade e lugar. Portanto, o processo da pesquisa narrativa é demarcado pela tridimensionalidade. A temporalidade deve ser compreendida considerando que a história narrada vai construindo sentido a partir do que se está vivendo no presente, articulando-se às experiências vividas no passado e se projetando para um futuro. Quando se atenta para esse movimento tridimensional da pesquisa narrativa, percebe-se que ele implica, necessariamente, outros dois 
movimentos a serem desenvolvidos, tanto pelo pesquisador quanto pelos participantes: um movimento que implica o olhar para si, para dentro, introspectivamente; e um olhar para fora, para os contextos a sua volta, um olhar extrospectivo (MELLO, 2004). o primeiro movimento implica a pessoa que se volta para o seu interior, para a sua subjetividade, para a constituição de si mesma, enquanto o segundo evoca o exterior, as intersubjetividades, as relações com o outro e com os contextos.

Ao assumir essa perspectiva teórico-metodológica, passamos a entender a pesquisa narrativa como um processo, o que implicaria potencialidades tanto no que se refere aos conhecimentos implícitos quanto a construções de identidades profissionais na docência. Assim, os integrantes dos grupos, enquanto pesquisadores vinculados à universidade, por meio da aproximação e do diálogo com os contextos das escolas, negociando contratos de confiança, propósitos, relacionamentos e colaboração, passam, a partir da experiência refletida, a recontextualizar o profissional docente, em um movimento permanente de indagação, problematização, experienciação e ressignificação do exercício docente.

Desse modo, ao focar nas vidas que emergem das narrativas, marcadas pelo cotidiano concreto em que vivem os indivíduos, compreendemos outras dimensões da pesquisa, mais especificamente do poder advindo da partilha de saberes, que só é possivel respeitando-se o outro. Assim, defendemos que compreender a experiência de outrem implica colocar-se ao lado deste outro, dialogando com sua experiência, para, através da indagação colaborativa, dar a esta o lugar apropriado nesse contexto de ressignificação. A ressignificação configura-se, assim, pelo processo criativo do professor de atribuir novos significados a partir do que já é conhecido, dando um outro sentido ao contexto em que está inserido, o que pode revelar contradições e conflitos, aspectos construtivos do processo que possibilitam um saber diferente.

Ferrarotti acrescenta que o que parece único, em se tratando desse tipo de metodologia de pesquisa, é a relação de interação que muda a atitude tradicional de pesquisar, passando a "não ser apenas uma comunicação metodológica, mas humanamente significativa, sendo essa significatividade, não um acréscimo facultativo moralizador, mas parte integrante e garantia de correção metodológica" (2014, p. 66).

Clandinin e Connelly (1988) enfatizam que o conhecimento prático dos professores é constituído de um conjunto de convicções e significados, que surgem tanto da experiência pessoal como social, e que se expressam nas ações, pressupondo uma relação dialética entre teoria e prática. É um conhecimento que vai sendo construído pela convergência de várias aprendizagens (dimensão teórica, dimensão experiencial, dimensão afetiva e outras), à medida que o profissional as confronta com a prática real e as internaliza em suas ações. Tais aprendizagens são construídas, inicialmente, nas primeiras experiências escolares, e acompanham a trajetória profissional dos professores, em vista da natureza dinâmica e complexa dos contextos em que atuam.

Clandinin e Connely nos dizem ainda que "fazemos parte do desfile que presumimos estudar" (2011, p. 120). A ideia do desfilar junto desmistifica a separação pesquisador-pesquisado, tornando-nos passageiros na mesma viagem. Para os autores, o fato de sermos organismos que, individual e socialmente, vivem vidas contadas, faz das narrativas boas formas de recuperar episódios dessas "vidas contadas" e da forma como nós humanos experimentamos o mundo, refletimos sobre nós mesmos, atribuímos sentidos, construímos identidades, formamos e avaliamos concep- 
ções, pensamentos e posicionamentos frente aos diversos desafios de viver o dia a dia de nossas vidas. No caso da formação docente, esses movimentos são fatores estruturantes do processo, que reforçam a necessidade de um olhar atento para si e para o outro, como importante e significativo, sem separações binárias, mas sim como seres formativos, em sua essência, e complexos, em seus percursos.

No caminho da abordagem qualitativa, a pesquisa a partir das narrativas (JOSSO, 2007; SOUZA, 2006a; 2006b) torna-se uma trilha teórico-metodológica com bastante pertinência no campo das ciências sociais e humanas. As narrativas podem ser utilizadas como técnica e forma de coletar dados, auxiliando na compreensão da formação docente, em diversos âmbitos, mas também como eventos de formação ativa, se transformadas em textos ou quaisquer outras expressões manifestas, especialmente se forem trocadas entre pares, com questões semelhantes, em suas práticas docentes. 0 trabalho com narrativas docentes favorece ver além das aparências, entender as subjetividades, a perspectiva dos envolvidos, e formas individuais e coletivas de desenvolver processos de formação profissional.

Encontramos em Dominicé (2008) uma observação sobre narrar-se ser muitas vezes lamentar-se, o que é considerado insuficiente pela autora. Muitas biografias de heróis deformam a realidade complexa da existência, embora vendam livros. A realidade da existência é complexa e como tal não faz heróis e sim pessoas comuns, que vivem à procura de sentido, que, quando partilhados, podem apresentar situações promissoras, mais realistas e menos idealizadas. Assim, atribuir sentidos ao vivido, sem cair na nostalgia ou na amargura, é teste para nossos trabalhos com narrativas, e um caminho possivel é contextualizar as narrativas de modo a dar uma moldura aos fatos, um entorno sociocultural específico, que pode produzir um outro entendimento, uma possibilidade de reconfiguração de fatos e dos sentimentos a eles associados.

A seguir, serão apresentados os caminhos que estamos trilhando, na tentativa de compartilharmos as experiências vividas e narradas pelos professores que atuam no primeiro ciclo, considerando que para Clandinin (2010) experiência é a própria vida.

A primeira investigação aqui apresentada, trazendo alguns resultados parciais, é parte de um projeto maior financiado pelo CNPq, intitulado “Desenvolvimento Profissional da Docência nos anos iniciais: ressignificando as aprendizagens", desenvolvido coletivamente pelo Grupo de Estudos e Pesquisas em Política e Formação Docente - GEPForDoc, do Programa de Pós-Graduação em Educação da Universidade Federal de Mato Grosso. O GEPForDoc vem se orientando por estudos e pesquisas na perspectiva do que se tem compreendido como desenvolvimento profissional docente e aprendizagens na docência (MONTEIRO, 2013; 2014a; 2014b; MONTEIRO et al, 2014; MONTEIRO, 2015), buscando aproximações com a pesquisa narrativa, enquanto método de investigação, denominada de Narrative inquiry (CLANDININ; CONNELLY, 2011).

A pesquisa coordenada por Monteiro (2015), com duração prevista de quatro anos, foi iniciada no primeiro semestre de 2015, tendo identificado, em seu levantamento inicial, junto à Secretaria Municipal de Educação de Cuiabá - SME, a existência de 22 (vinte e duas) escolas que atendem ao 1o Ciclo-anos iniciais. Nessas 22 escolas foram identificados 298 docentes participantes. Na primeira etapa da pesquisa, realizamos a caracterização do corpo docente das escolas municipais que atendem ao primeiro ciclo do ensino fundamental em Cuiabá-MT, com vistas a compreender quem é o profissional que atua nesse nível de

1 Projeto de pesquisa Edital Universal/2014, CNPq. 
ensino, sua formação inicial, vínculo empregatício e tempo de experiência na docência. Nessas escolas, para a caracterização docente, foi realizado um levantamento de informações iniciais, fornecidas pela gestão escolar e pelos próprios docentes. Tais informações foram registradas em uma ficha criada pelo grupo de pesquisa.

Na segunda etapa da pesquisa, foram escolhidas três escolas municipais que possuíam apenas o 1o ciclo, atendendo a alunos na faixa etária de 6 a 9 anos, para a produção dos vários textos de campo narrativos. Tais narrativas, construídas pelos participantes da pesquisa, visam contribuir na compreensão dos contextos e lugares onde estes se inserem e nos quais desenvolvem e constroem seus conhecimentos em ação. As narrativas orais e escritas apresentadas neste texto foram oriundas de registros em encontros da pesquisa, em que propusemos aos professores compartilharem as experiências e aprendizagens vividas com as turmas em que estavam atuando. Consideramos cada escola como estudos de caso, com suas situações particulares, compostos por um conjunto de textos de campo, com descrições dos contextos, acontecimentos, eventos, e pelas narrativas dos professores, elaboradas em diferentes momentos, em que transformam os acontecimentos e dilemas em uma história.

No que se refere ao levantamento inicial sobre a formação dos docentes que atendem ao 1o ciclo, identificamos que $80 \%$ apresentam graduação em Pedagogia, o que mostra o atendimento das diretrizes oficiais, em relação aos professores dos anos iniciais do primeiro ciclo do ensino fundamental. Entretanto, 60\% desses professores foram formados em instituições de ensino superior da rede particular.

Em se tratando da formação continuada, observamos que $71 \%$ dos professores realizaram curso de pós-graduação lato-sensu. Segundo Day (2005), os professores são sujeitos ativos e precisam estar preparados para cumprir seus fins educativos, devendo demonstrar compromisso e entusiasmo frente à aprendizagem contínua. Os professores pesquisados, ao buscarem conhecimentos e cursos de pósgraduação, para subsidiar a ação docente, vão ao encontro dessa perspectiva. Pacheco e Flores (1999) por sua vez apontam para a necessidade do processo de inserção profissional centrar-se no desenvolvimento da construção das identidades docentes, através de uma articulação entre biografia pessoal, prática reflexiva, apoio dos pares e uma conscientização crescente do contínuo aprimoramento profissional.

Em relação ao vínculo empregatício, 53\% são efetivos e $43 \%$ têm contratos temporários. O grande percentual de professores temporários demonstra a carência de concursos para a efetivação do quadro docente de professores da rede municipal de ensino, além de demonstrar uma política de não valorização desses professores dos anos iniciais, ocasionando a rotatividade dos professores no ensino fundamental.

Já no que se refere ao tempo de docência, os dados indicam que a maior parte dos docentes, em relação ao tempo de experiência na docência, é considerada experiente, totalizando $88 \%$, que apresentam período superior a cinco anos de docência (conforme estudos de Marcelo Garcia, 2009; e de Garcia e Vaillant, 2009). Mesmo entre os contratados, identificamos professores com mais de cinco anos de docência. Para Day (2001, p. 16), "os professores se constituem no maior trunfo da escola", são sujeitos ativos que, com seu potencial de desenvolvimento, aprendizado e participação na tomada de decisões coletivas, se constituem em peças chave para um ensino de qualidade.

No tópico a seguir, damos um exemplo de como fomos compondo, narrativamente, os 
textos de campo do estudo, procurando entrelaçar contextos, tempos, aprendizagens, experiências e significados resultantes das narrativas produzidas nos encontros de pesquisa. Para Clandinin e Connelly (2011, p. 128):

Compor textos de campo significa estar alerta para as coisas que os participantes fazem e dizem como parte de sua experiência em curso e isso significa manter registros sobre como eles vivenciam a experiência de estar na pesquisa. Os participantes também têm sentimentos e pensamentos sobre a pesquisa.

\section{Significados compartilhados: da experiência vivida ao conhecimento da experiência}

As narrativas escritas apresentadas neste texto são oriundas de registros em um dos encontros da pesquisa, durante o ano de 2015, em que propusemos aos professores compartilharem as experiências e aprendizagens vividas com as turmas em que estavam atuando, sem esquecer que a indagação narrativa deve nascer da experiência e retornar a ela, numa evolução cíclica do viver, contar, recontar e reviver (CLANDININ; CONNELLY, 2011). Tais encontros foram gravados em vídeo, acompanhados de narrativas escritas. As professoras participantes encontram-se em diferentes etapas de desenvolvimento profissional e com experiências diversas no exercício da docência, tanto em relação ao tempo quanto ao nível de ensino em que já atuaram, embora atualmente todas se encontrem em exercício no 1 o ciclo.

As narrativas escritas vão compondo tramas com outras histórias, possibilidades de sentidos e significados, nos permitindo compreender como são traçadas as estratégias de troca de experiências sobre as atividades que visam a aprendizagem dos alunos, os sentidos construídos na experiência como um lugar de criação do possivel, os significados que surgem a partir das relações estabelecidas en- tre as tensões e os desafios enfrentados, no contexto específico do trabalho, com projetos, ao mesmo tempo em que vão ampliando, negociando e ressignificando esse lugar no cotidiano escolar. Apontam também alternativas, compartilhadas nas experiências vivenciadas, revelando o modo como organizam a aula, interagem com seus pares e como o ensino-aprendizagem é desenvolvido de maneira mais ativa.

Atualmente trabalho com duas turmas de 30 ano e vejo como ponto positivo ter acompanhado essa turma desde 2014 quando começamos no 1o ano. Sempre fui contra esse negócio de acompanhar turmas. (Professora Cristiane)

Quando assumi a turma me deparei com algumas situações desafiadoras, pois na sala há alunos que estão com o desenvolvimento bem adiantado, enquanto um número significativo de alunos ainda requer atenção maior em todos os sentidos da aprendizagem. Então me questiono todo dia sobre qual seria a melhor forma de ligar com isso... (Professora Rosângela)

0 processo de ensino aprendizado não é fácil...estou trabalhando com o 1 ano, um desafio após mais de cinco anos sem atuar, estou reinventando, procurando coisas diferentes, em sala são 28 alunos, estrutura física precária, mas não me falta vontade em ensinar. (Professora Paula)

Por que até alguma coisa que a gente está fazendo lá no 10 ano pode ajudar muito as professoras que estão no 2 o ano, ou seja, porque tem alguns alunos que ainda não avançaram, têm algum tipo de dificuldade, então precisam desse avanço, e às vezes alguma coisa que o 10 ano está propondo serve bem certinho para esses alunos do 20 ano. Então, esse meio de comunicação que a gente fez na escola, entre e-mail e whats....e a própria coordenação, está fazendo essa intervenção, Olha Dilce a professora Ilza fez isso, isso aqui.... Que é essa troca. (Professora Dilce)

Então, tem um grupo que fica para todos os funcionários e um grupo que fica para os professores fazerem essa troca de experiência, com isso, 
com essa troca de experiência, vai melhorando, eu vou cobrando do outro professor: professora, vamos fazer outra coisa porque eu acho que nessa parte a gente estagnou, vamos melhorar! Trabalho como um todo, então, por exemplo, o trabalho com o 2 o ano é um planejamento para o 2o ano matutino e vespertino, porém nós temos o projeto, e o projeto não é para o matutino e vespertino é para cada sala, aquela sala de manhã e tarde é um projeto, aquela outra sala de manhã e de tarde é outro projeto, então elas têm que fazer essa troca de experiência. 0 projeto em si foi dificil de finalizar, porque um é da manhã e o outro é da tarde, então tem essa dificuldade, elas têm que trocar ideias, a noite, finais de semana... (Professora Maria)

Também só colocar aqui... Essa minha primeira experiência... o professor tem que ter essa oportunidade de chegar. Porque tudo tem que ter um começo e então tem o professor novato. Então quem já ta há mais tempo é... Acolhe aquele professor, né? Acolhe no local, olha aqui funciona assim e tal... (Professora Ane)

O que a gente tem visto que na escola é assim, os 30 anos, fazem um projeto só de aula da semana, e esse projeto a gente troca, então nos somos quatro, essa semana eu faço, na semana seguinte faz a outra, na semana seguinte faz a outra, e a gente troca, faz essa troca pra ter mais tempo na hora de dar, pra fazer uma atividade legal e tem dado resultado, lógico a nossa coordenadora... (Professora Ilza)

As narrativas das professoras envolvidas nesta pesquisa revelam as contradições presentes no exercício da docência, desvelando maneiras diferentes de viver os contextos em que elas atuam, marcados, para além de suas práticas, por pessoas, lugares, tempos e sentimentos de vida singular-plural (FERRAROTTI, 2014).

São enfatizadas as condições precárias do trabalho por um grupo de uma das escolas, acrescentando que isso dificulta pensar esse espaço como de reflexão e produção de conhecimentos. As situações de dificuldade, muito embora perturbadoras do fazer profissional, tornaram-se, para algumas, um desafio, conduzindo à problematização e à tentativa de resolução dos problemas, passando a ser potencializadoras do desenvolvimento profissional. Já outro grupo que vivencia em sua escola um trabalho cooperativo reforça a ideia da escola enquanto espaço relacional e a necessidade de se cultivar o diálogo, ao mesmo tempo em que evidenciam suas aprendizagens sobre o conhecimento prático.

A segunda investigação aqui apresentada vem sendo desenvolvida, desde 2009, na Faculdade de Formação de Professores da UERJ (FFP/ UERJ), campus de São Gonçalo, região metropolitana do Estado do Rio de Janeiro, que chamamos Residência Pedagógica, e envolve as três funções da Universidade, pesquisa, ensino e extensão, de uma forma orgânica. Trabalhamos com egressos dos cursos de Licenciatura da FFP/UERJ, que estejam inseridos na docência, acompanhando sua atuação e servindo de suporte para refletir e ressignificar suas ações pedagógicas, projeto de pesquisa cadastrado institucionalmente, que vem produzindo textos e apresentações em eventos. Como ensino, propomos o espaço da Residência Pedagógica, no qual, a partir de encontros presenciais, refletimos e teorizamos sobre nossas práticas e sobre as atividades formativas vivenciadas e as inserções na vida profissional. Como extensão, curso também cadastrado institucionalmente, propomos atividades conjuntas entre a FFP/UERJ e as escolas nas quais se inserem os docentes participantes, com vistas a desenvolver a articulação universidade e escola básica, tarefa de uma instituição pública que preza por suas funções sociais. Já temos uma longa trajetória de pesquisa, na área de formação de professores, utilizando metodologias qualitativas, narrativas docentes e refletindo sobre processos que acontecem nos espaços formativos nos quais transitamos (FONTOURA, 2015; 2014a; 2014b; 2014c; 2014d; 2013a; 2013b; 2011a; 2011b; 2011c; 2009; 2008a; 2008b; 2007; 
FONTOURA et al, 2014; 2013; 2010; FONTOURA; PIERRO, 2015; 2014; FONTOURA, PIERRO; CHAVES, 2011; FONTOURA; VERÍSSIMO, 2014).

Uma das vantagens de narrar a partir, por exemplo, da escrita, nosso foco nesse texto, é dar liberdade para os sujeitos envolvidos na pesquisa exprimirem suas formas de pensar, sentir, remetendo-os a reflexões individuais e conjuntas sobre as questões a respeito do que fazem, do que sentem; suas visões de mundo, modos de pensamento, significados da docência e de como concebem escola, ensino e, principalmente, como constituem sua identidade docente, o que Souza enfatiza, ao afirmar que "o ato de lembrar/narrar possibilita ao ator reconstruir experiências, refletir sobre dispositivos formativos e criar espaço para compreensão da sua própria prática" (2004, p. 142). As narrativas mostram os caminhos percorridos ao longo da formação destes sujeitos, sendo então de suma importância para a formação ao longo da vida, ou, como preconiza Nóvoa, estas reflexões possibilitam "reconstruir o conhecimento profissional a partir de uma reflexão prática e deliberada" onde devem "saber analisar [...] e analisar-se" (2002, p. 27).

No grupo de Residência Pedagógica são feitas atividades diversas, nas quais se discute desde aportes teóricos até vivências em escolas, buscando significar o que acontece, quando nos tornamos professores, e como lidar com os dilemas da prática docente. $\mathrm{Na}$ lista de e-mails há uma intensa troca de textos, experiências, atividades, que mantém o grupo em contato o tempo todo, alimentando as relações profissionais e interpessoais. Tudo o que acontece, seja nos encontros seja no dia a dia, é registrado no caderno de campo de cada um dos envolvidos, e esse material se torna um produto comum, já tendo alimentado uma publicação conjunta (FONTOURA, 2011a), e algumas apresentações em eventos cientí- ficos da área, o que potencializa os docentes envolvidos. O material coletado é analisado através da tematização proposta por Fontoura, procedimento no qual a análise consiste em reflexão rigorosa sobre os materiais, seguindo as etapas de categorização indicadas pela autora, que reforça que "a análise temática consiste em descobrir os núcleos de sentido que compõem a comunicação e cuja frequência de aparição (desde muito frequente até apenas uma vez) pode significar alguma coisa para o objetivo analítico escolhido" (2011b, p. 72). Esta técnica pode representar um marco diferencial em investigações que passem pelas mesmas temáticas, pois depende não exclusivamente dos dados, mas sim de quem executa a seleção e a tematização.

Como procedimentos de abordagem do campo, foram feitas ainda visitas às escolas parceiras e observações nas salas das professoras envolvidas no Projeto, assim como atividades a partir de solicitações das escolas parceiras, como palestras e cursos de extensão, para docentes interessados, e não necessariamente frequentando a Residência Pedagógica. No trabalho desenvolvido, articulamos sempre teoria e prática, por acreditarmos que a atividade teórica é a elaboração ou a transformação da realidade, e que a consciência se produz mediante o conhecimento da realidade e do querer algo novo. Mas a atividade teórica por si só não leva à transformação. Ela necessita tornar-se ação; fazer-se atividade prática, que é a realização desse saber-e-querer-algonovo; é, pois, necessariamente, transformadora, e nesse sentido é práxis: interpretação real (desejo do novo) e transformação da realidade (realização desse desejo). A atividade teórica realiza-se na prática, através de mediações sem as quais as ações efetivas não serão desenvolvidas: educação das consciências, organização dos meios materiais e planos concretos de ação. 
Caminhando nessa direção, busca-se configurar práticas de formação com base em histórias de si (JOSSO, 2010), de modo que professores possam reconstruir suas práticas docentes, construir pontes entre a realidade de seu trabalho e os saberes construídos em seus (per)cursos. Aponta a autora que as nossas histórias de vida estão ligadas à nossa "busca de si e de nós" (2010, p. 122, grifos da autora), segundo nossas necessidades e desejos, em nossos agrupamentos. Diz ainda que a evolução de sentidos que damos às nossas vidas se expressa em nossas itinerâncias, explorações que fazemos reiteradamente de nossos desejos e necessidades, o que se traduz em uma aparente inconstância, que nada mais é do que as errâncias associadas à nossa busca de si.

Corroborando as posturas trazidas pelos autores da área, na Residência Pedagógica produzimos conhecimento como grupo de ensino que somos, em uma estrutura de formação que conduz os processos de forma democrática e criativa, característica presente nas exigências de desempenho do professor, mas em geral ausente de práticas formativas e, mais ainda, de políticas de formação voltadas para os interesses de mercado e produtividade presentes, muitas vezes, em propostas oficiais.

Uma das atividades que consideramos mais significativa para o que pretendemos no presente texto foi a proposta de escrita de uma experiência vivida enquanto discente que tenha impactado a prática do professor na atualidade. Um dos temas que emergiu fala de modelos de como ser ou não ser professor, tanto na linha de "amei minha professora de história na oitava série e decidi ser professora de história", ou "sabe como é, a gente gosta da matéria que tem professor que sabe e que mostra pra gente que sabe e que gosta dos alunos e de ensinar", ou ainda: "o professor de ciências só gritava com a gente, nada de ciências que era bom, ou seja, não aprendi ciências, $e$ até hoje não posso nem ouvir falar no assunto sem me arrepiar, e o pior é que às vezes tenho que substituir a professora de ciências - dou português e literatura - e aí faço literatura $e$ ciências até funciona".

Vimos em nosso suporte de literatura a questão de modelos como sendo de importância, mas não como preconizam propostas oficiais de formação, como espelhos a nos mirarmos e perpetuarmos algo aprendido, de forma engessada e correta. Longe disso, a partir de narrativas dos participantes, verificamos a importância de ressignificar marcas que recebemos daqueles em que nos miramos, quando aprendíamos a ensinar, mas enquanto constituintes de nosso eu docente, para serem refletidas, questionadas, copiadas se forem assim consideradas boas, mas sempre levando nossa identidade como um fator preponderante. Não somos o outro a ser mimetizado, mas somos nós em desenvolvimento que carregamos as marcas do outro em nós.

Outro tema presente nos escritos docentes foi relacionado à formação recebida, em geral considerada insuficiente para preparar o professor para a tarefa docente, "nunca havia pensado em muitas situações que tenho vivido, não sei nem como agir às vezes [...] e o pior é que não tenho a quem recorrer"; "nem no curso normal nem na faculdade discutimos coisas que se passam na sala de aula e na escola $e$ aí sobra pro professor resolver, por exemplo, como lido com um aluno que está se drogando e vendendo drogas na escola?"; "esse ano a SME deu uma formação na Semana Pedagógica e a gente só ficava rindo por dentro: de que escola aquela pessoa estava falando? Certamente não era a nossa [...] uma sensação muito grande de tempo perdido [...]"

As percepções que vamos construindo, a partir das experiências formativas vividas, vão nos constituindo nos docentes que somos; mas 
é impossivel não ouvirmos as vozes que clamam por formações consistentes, condizentes com as reais condições de trabalho na docência, que se valham de pares para (co)construir esta docência que preconizamos. Muitas vezes, queixamo-nos por não sabermos fazer diferente. Porém, ao trocarmos narrativas, por semelhanças e identificações, podemos nos sentir parte de um coletivo que partilha obstáculos e desafios similares, e que pode se fortalecer para fazer do lugar da formação um espaço de crescimento, pessoal e profissional, de aprendizagens individuais e coletivas, de troca de possibilidades, que sabemos múltiplas e potentes.

Um terceiro tema, que se entrelaça aos anteriores, trouxe a questão das condições de trabalho, consideradas muito aquém das suficientes para a realização da ação docente nos moldes que defendemos e acreditamos: "tem dia que não temos nem giz, e fica dificil até passar alguma atividade"; "nosso salário atrasou dois meses e a Prefeitura nem se importou com isso, disse que não tinha como pagar e pronto..."; "gosto do que faço, sei que ganho pouco, mas como ainda moro em casa de meus pais até ajudo na feira, só que acho um absurdo um trabalho de responsabilidade como esse receber tão pouco"; "a sociedade não valoriza o professor, pois, se valorizasse, não ganharíamos tão pouco e a nossa greve teria um impacto maior; parece que não faz nenhuma diferença estar ou não estar trabalhando, dá vontade de desistir e fazer outra coisa".

Alguns dos extratos de fala selecionados apontam para um descrédito com relação às condições de trabalho e suas possibilidades de melhoria; mas temos Freire (1969) para nos ajudar a pensar na educação como prática da liberdade, tirando o que ensina e aprende da opressão, formando educadores em diálogo, eliminando a concepção binária de educação, que, para o autor, é reflexo da sociedade de opressão, tornada dimensão da "cultura do silêncio", a educação bancária estimula e favorece a contradição, situação na qual educador é quem pensa e os alunos os que são pensados. Caminhamos com pessoas pensantes e optantes todo o tempo de nossa investigação e de nossos trabalhos formativos.

\section{Considerações}

Postulamos no presente texto que o desenvolvimento da identidade profissional não é um processo linear e sim um lugar de lutas e de conflitos e de construção de maneiras de ser e de estar na profissão. É nesse processo de desenvolvimento do sentimento de pertença e da identidade que cada um se apropria do sentido da sua história pessoal/profissional, reconstruindo identidades, para assimilar mudanças, novas perspectivas, inovações (NÓVOA, 1992; 1995).

Percebemos nas experiências apresentadas que se tornou referência para os participantes das pesquisas, aqui em diálogo, a questão relacional, tanto na pesquisa narrativa quanto no entendimento da profissão docente, o que significa repensar como nos relacionamos com as outras pessoas, na busca de construir autonomia e compromisso profissional. A partir das indagações em torno de como os professores que atuam no primeiro ciclo significam e ressignificam o trabalho docente, como suas experiências vividas na docência são percebidas, narradas, e como explicam a relação destas com o processo de aprender a ensinar, passamos a viver junto a, buscando estudar o desenvolvimento profissional docente tomando a experiência/ sentido, contando e recontando histórias narrativamente, enfatizando principalmente sua dimensão temporal e relacional, em prol de práticas de formação e investigação socialmente mais justas e de transformações educacionais significativas (ZEICHNER, 2009). 
Embora esse processo revele tamanha complexidade e multidimensionalidade, é uma necessidade individual/coletiva e organizacional que pressupõe se comprometer com uma aprendizagem contínua e com o desejo de marcar a vida dos alunos (DAY, 2001). Significa também o processo pelo qual os professores revivem, renovam e ampliam seu compromisso, refletindo sobre os propósitos éticos e morais do ensino, considerando que as consequências desses compromissos se alimentam das experiências (DAY, 2001; 2005; CONTRERAS, 2002; ZEICHNER, 2008). Assim, o desenvolvimento profissional está intimamente entrelaçado ao movimento de significações e ressignificações atribuídos à dinâmica profissional num contexto situado. Ou seja, o professor necessita explicar a si mesmo, repensar como constrói sua prática profissional, para que possa entender as aprendizagens profissionais da docência a partir de múltiplos contextos e diversas experiências vivenciadas com potencialidade educativa.

Por outro lado, a imersão na escola e o diálogo com as experiências de trabalhar colaborativamente num contexto marcado por tensões, desafios e possibilidades, nos fez reconhecer que a opção metodológica pela narrativa colocava em confronto algumas de nossas concepções, pois a relação dialética revelada pela pesquisa vai além das experiências individuais e coletivas, se constituindo a partir das características mais amplas do contexto.

Nas investigações aqui em diálogo, a formação docente mostra-se muito interligada à pesquisa em sala de aula, à pesquisa em ambiente de trabalho e não apenas à modalidade de curso de aperfeiçoamento, palestras, oficinas, que informam sobre determinados tópicos. Não pode, portanto, ser entendida como uma ação em tempo e espaço isolados do contexto de atuação do professor, mas uma formação cotidiana que permita escutar, per- guntar e confrontar experiências de vida. Para tanto, os espaços de formação em que acreditamos atuam em busca da melhoria na qualidade do ensino e da boa atuação dos profissionais envolvidos no processo. Temos clareza, a partir de nossa experiência, que os professores aprendem muito compartilhando sua profissão, seus problemas, no contexto de um trabalho reflexivo, sendo que é no exercício do trabalho reflexivo que, de fato, o professor produz sua profissionalidade.

Apoiados em Freire (1996), afirmamos que a formação docente deve se fazer aliada do exercício da criticidade, que sugere a promoção da curiosidade ingênua à curiosidade epistemológica, e do reconhecimento do valor das emoções, da sensibilidade, da afetividade, da intuição ou da adivinhação. É possível perceber avanços nos discursos pedagógicos, mas sem uma continuidade nas políticas, para que o professor possa se apropriar dos conhecimentos e incorporá-los à sua prática, os efeitos positivos se perdem. Torna-se, então, essencial, desenvolver estratégias e capacidades para aprender com os outros, a partir dos outros e para os outros, pois, quando a profissão docente é respeitada e os professores apoiados na sua aprendizagem profissional, é mais provável que ocorra uma melhoria na qualidade da aprendizagem dos alunos.

As narrativas podem ser vistas como maneiras de relatar os processos de emancipação que marcam nossos percursos pessoais e ao mesmo tempo desvelam enraizamentos sociais, dando luz a possibilidades de referência para um futuro mais coerente com os tempos em que vivemos. Como vimos, as narrativas de si expressam sentimentos, ilusões/desilusões, de forma distinta do "muro das lamentações", tão presente quando nos reunimos em salas de professores, conselhos de classe ou mesmo em momentos informais no espaço escolar. 
Finalizamos, reiterando que o professor forma a si mesmo através das suas inúmeras interações, não apenas com o conhecimento e as teorias aprendidas, mas com a sua prática e a de seus professores e colegas, em situações de ensino-aprendizagem com as quais interagiu durante toda a sua vida. Portanto, a formação apoiada no conceito de desenvolvimento profissional docente pode assumir as características de um processo de formação emancipatória, apostando no fortalecimento do professor, seus saberes e suas práticas, como aspecto fundamental que contribui para

\section{Referências}

CLANDININ, D. Jean. Potentials and possibilities for narrative inquiry. In: CAMPBELL, M.; THOMPSON, L. (Eds.). Issues of identity in music education: narratives and practice advances in music education. Charlotte, NC: Information Age Publishing, 2010. p. $1-11$.

CLANDININ, D. Jean; CONNELlY, F. Michael. Pesquisa narrativa: experiência e história em pesquisa qualitativa. Tradução do Grupo de Pesquisa Narrativa e Educação de Professores ILEEI/UFU. Uberlândia: EDUFU, 2011.

Conocimiento práctico personal de los profesores: imagen y unidad narrativa. In: ANGULO, L. M. V. (Org.). Conocimiento, creencias y teorías de los profesores. Alcoy: Editorial Marfil, 1988. p. 63-86.

CONTRERAS, Jose. A autonomia de professor. Tradução de Sandra Trabucco Valenzuela; revisão técnica, apresentação e notas à edição brasileira de Selma Garrido Pimenta. São Paulo: Cortez, 2002.

DAY, Christopher. Formar docentes: cómo, cuando y en qué condiciones aprende el profesorado. Tradução de Pablo Manzano. Madrid: NARCEA S.A., 2005.

ra, 2004.

A paixão pelo ensino. Porto: Porto Edito-

Desenvolvimento profissional de profes-

sores: os desafios da aprendizagem permanente. uma inserção docente crítica e criativa na escola e na sociedade.

Diante das reflexões apresentadas, vamos compondo e recompondo a docência como experiência-saber dotada de sentidos e significados, lugar de produção de subjetividades e intersubjetividades, num movimento de ressignificação, ancorado pelos conhecimentos problematizados no entrecruzamento de diferentes culturas em um contexto situado - a escola, lugar privilegiado de aprendizagem e de desenvolvimento profissional da docência.

Porto: Porto Editora, 2001.

DOMINICÉ, Pierre. Biografização e mundialização: dois desafios contraditórios e complementares. In: PASSEGGI, M. C.; SOUZA, E. C. (Orgs.). (Auto)Biografia: formação, territórios e saberes. Natal: EDUFRN; São Paulo: Paulus, 2008. p. 25-46.

ESTRELA, Maria Tereza. Questões de profissionalidade e profissionalismo docente. In: TEIXEIRA, M. (Org.). Ser professor no limiar do século XXI. Porto: ISET, 2001. p. 113-141.

FERRAROTTI, Franco. História e histórias de vida. O método biográfico nas Ciências Sociais. Tradução de Carlos Eduardo Galvão Braga e Maria da Conceição Passeggi. Natal: EDUFRN, 2014.

FONTOURA, Helena Amaral. Formação docente e diversidade na educação básica. In: RIOS, Jane A. V. P. (Org.). Docência na educação básica. Salvador: EDUNEB, 2015. p. 67-100.

Percepções sobre a Residência Pedagógica da Faculdade de Formação de Professores da UERJ: relatos de participantes. In: SEMINÁRIO ESTADUAL DA ANPAE, 4., 2014, Niterói. 25 anos da Constituição Cidadã: repercussões nas políticas públicas de Educação. Anais... Niterói: NITPRESS; ANPAE RJ, 2014a. p. 1-11

- Conversas sobre formação de profes- 
sores na Residência Pedagógica da Faculdade de Formação de Professores da UERJ: memórias e narrativas como construtores de espaços de possibilidades. In: ALVARENGA, Marcia Soares; MAURícIO, Lucia Velloso; RIBETTO, Anelice. (Orgs.). Vozes da educação: formação docente - experiências, políticas e memórias polifônicas. Rio de Janeiro: EdUERJ, 2014b. p. 47-61.

. De Maktub a serendipidade na formação de professores. In: FONTOURA, H. A.; LELIS, I. A. O.; CHAVES, I. M. B. (Orgs.). Espaços formativos, memórias e narrativas. Curitiba: CRV, 2014c. p. 65-77.

Inclusion and teachers' training: reflecting upon hows and whys In: WORLD ASSEMBLY OF THE INTERNATIONAL COUNCIL ON EDUCATION FOR TEACHING, 58., Oshawa, 2014. Moving Forward in Curriculum, Pedagogy and Leadership. Anais... Oshawa, Canadá: UOIT, 2014d. v.1. p. 151-157.

Ensino superior e educação básica: a construção de uma política de formação de professores In: PIMENTEL, S. C.; LOPES, A. L.; SOUZA, L. D. A. S. (Orgs.). Formação de professores: políticas, saberes e práticas. Feira de Santana, BA: Shekinah; FAPESB, 2013a. v.1. p. 17-34.

Memórias escolares de professores/as em formação In: SEMINÁRIO SOBRE A PRODUÇÃO DO CONHECIMENTO EM EDUCAÇÃO, 7., 2013, Campinas. Política Educacional do século XXI: paradoxos, limites e possibilidades. Anais... Campinas, SP: PUC Campinas, 2013b. p. 489-495.

- Residência pedagógica: construindo pontes entre a universidade e a escola básica. In: INTERNATIONAL CONGRESS OF AMERICANISTS, 54., 2012, Viena. Building dialogues in the Americas. Anais... Viena: Institut des Amériques, 2012. p. 1-12.

Residência pedagógica: investigação-ação com professores egressos da Faculdade de Formação de Professores da UERJ. Revista de Educação Pública, Cuiabá, UFMT, v. 20, p. 307-322, 2011a.

Analisando dados qualitativos através da tematização. In: FONTOURA, H. A. (Org.). Formação de professores e diversidades culturais: múltiplos olhares em pesquisa. Niterói: Intertexto, 2011b. p. 61-82. (Coleção Educação e Vida Nacional, 3).

. (Org.). Residência pedagógica: percursos de formação e experiências docentes na Faculdade de Formação de Professores da UERJ. Niterói: Intertexto, 2011c.

Tecendo experiências na Faculdade de Formação de Professores da UERJ em São Gonçalo, RJ: relatos de pesquisa etnográfica. In: ENCONTRO DE PESQUISA EM EDUCAÇÃO DA REGIÃO SUDESTE, 9., 2009, São Carlos. Anais... São Carlos, SP: ANPED, 2009. p. 1-12.

- (Coord.) Percursos de formação e experiências docentes: um estudo com egressos do curso de Pedagogia da Faculdade de Formação de Professores da UERJ. Projeto de Pesquisa CNPq Faculdade de Formação de Professores, Universidade do Estado do Rio de Janeiro. Rio de Janeiro: UERJ, 2008a. mimeo.

. Formando professores que aprendem a partir dos relatos: uma experiência na Faculdade de Formação de Professores (FFP) da UERJ. Revista FAEEBA, v. 17, p. 137-146, 2008b.

. (Org.). Diálogos em formação de profes-

sores: pesquisas e práticas. Niterói: Intertexto, 2007.

FONTOURA, Helena Amaral; BRAGANÇA, Inês Ferreira Souza; GASPARELLO, Vania Medeiros. Residência Pedagógica: experiências em formação com egressos da Faculdade de Formação de Professores da UERJ. In: FONTOURA, H. A.; TAVARES, M. T. G. (Orgs.). Trabalho docente: experiências formativas e inserção profissional. Niterói: Intertexto, 2013. v. 8. p. 1-16.

FONTOURA, Helena Amaral; FERNANDES, Glaucia Braga Ladeira; MAGALHÃES, Carolina; SILVA, Katiuscia; SOARES, Vivian. Residência Pedagógica: um trabalho com egressos de Pedagogia da Faculdade de Formação de Professores da UERJ de São Gonçalo. In: SEMINÁRIO VOZES DA EDUCAÇÃO: formação de professores/as, narrativas, políticas e memórias, 4., 2010, São Gonçalo. Anais... São Gonçalo, RJ: UERJ/ FFP, 2010.

FONTOURA, Helena Amaral; LELIS, Isabel Alice Monteiro; CHAVES, Iduina Mont'Alverne Braun. Narrativas entrelaçadas em espaços-tempos plurais 
In: FONTOURA, H. A.; LELIS, I. A. M.; CHAVES, I. M. B. (Orgs.). Espaços formativos, memórias e narrativas. Curitiba: CRV, 2014. p. 15-23.

FONTOURA, Helena Amaral; PIERRO, Gianine Maria Souza. Universidade e escola: compartilhando percursos formativos. In: FLORES, M. A.; FERREIRA, F. I. (Orgs.). Formação e trabalho docente: projetos, políticas e práticas. Santo Tirso, Portugal: De Facto Editora, 2015. p. 143-161.

FONTOURA, Helena Amaral; PIERRO, Gianine Maria Souza. A Universidade e a escola básica: caminhos na investigação de processos de ensino-aprendizagem. In: INTERNATIONAL STUDY ASSOCIATION ON TEACHERS AND TEACHING - ISATT, 8., 2014, Braga, Portugal. Formação e trabalho docente na sociedade da aprendizagem. Anais... Braga, Portugal: Universidade do Minho, 2014. p. 234-242.

FONTOURA, Helena Amaral; PIERRO, Gianine; CHAVES, Iduina. Didática: do ofício e da arte de ensinar. Niterói: Intertexto, 2011.

FONTOURA, Helena Amaral; VERÍSSIMO, Maria Luiza. Formação docente: memórias, narrativas e cotidianos. Teias, Rio de Janeiro, v. 14, p. 4-12, 2014.

FREIRE, Paulo. Pedagogia da autonomia. São Paulo: Paz e Terra, 1996.

FREIRE, Paulo. Pedagogia do oprimido. Rio de Janeiro: Paz e Terra, 1969.

GALVÃO, Cecília. Narrativas em educação. Ciência e Educação, v. 11, n. 2, p. 327-345, 2005.

GATTI, Bernardete A. Formação de professores: condições e problemas atuais. Revista Brasileira de Formação de Professores - RBFP, v. 1, n. 1, p. 90-102, mai. 2009.

GATTI, Bernardete A. Formação de professores no Brasil: características e problemas. Educação e Sociedade, Campinas, v. 31 , n. 113 , p. 1355-1379, out./ dez. 2010.

GATTI, Bernardete A. Formação inicial de professores para a educação básica: pesquisas e políticas educacionais. Estudos em Avaliação Educacional, v. 25, n. 57, p. 24-54, jan./abr. 2014.
Gatti, Bernadete A.; Barreto, Elba S. S.; ANDRÉ, Marli E. D. Políticas docentes no Brasil: um estado da arte. Brasília: UNESCO, 2011. Disponível em: <http://unesdoc.unesco.org/images/0021/002121/212183por. pdf>. Acesso em: 27 out. 2014.

GATTI, Bernadete A.; BARRETO, Elba. S. (Coords.). Professores do Brasil: impasses e desafios. Brasília, DF: UNESCO, 2009.

IMBERNÓN, Francisco. La profesión docente desde el punto de vista internacional: que dicen los informes? Revista de Educación, n. 340, p. 41-49, 2006.

JOSSO, Marie C. Experiências de vida e formação. 2. ed. rev. e ampl. Natal: EDUFRN; São Paulo: Paulus, 2010.

JOSSO, Marie C. A transformação de si a partir da narração de história de vida. Educação, Ano XXX, n. 3 (63), p. 413-438, set./dez. 2007.

MARCELO GARCIA, C. Formação de professores: para uma mudança educativa. Porto: Porto Editora, 1999.

MARCELO GARCIA, C. A formação de professores: novas perspectivas baseadas na investigação sobre o pensamento do professor. In: NÓVOA, A. (Org.). Os professores e sua formação. 2. ed. Lisboa: Publicações Dom Quixote, 1995. p. 51-76.

MARCELO GARCIA, Carlos. Desenvolvimento profissional docente: passado e futuro. Sísifo, Revista de Ciências da Educação, n. 8, p. 7-22, 2009.

MARCELO GARCIA, Carlos; VAILLANT, D. ?Desarrolo profesional docente: como se aprende a ensinar? Madrid: Narcea. 2009.

MELLO, Dilma M. de. Histórias de subversão do currículo, conflitos e resistências: buscando espaço para a formação do professor na aula de língua inglesa do Curso de Letras. São Paulo, 2004. 200 f. Tese (Doutorado em Linguística) - Programa de Pós-Graduação em Linguística Aplicada e Estudos da Linguagem, Pontificia Universidade Católica de São Paulo, São Paulo, 2004.

MONTEIRO, Filomena M. Arruda. Práticas de investigação narrativa com professores em exercício: contribuições significativas ao desenvolvimento profis- 
sional. Teias, Rio de Janeiro, v. 15, p. 118-129, 2014 a.

. Práticas de formação e diversidade: uma experiência de investigação-formação. Educação em Foco, Juiz de Fora, v. 19, p. 129-152, 2014 b.

. Desenvolvimento profissional da docência: sentidos e significados compartilhados em pesquisa narrativa. In: CAVALCANTE, Maria Marina Dias et al. (Orgs.). Didática e a prática de ensino: diálogos sobre a escola, a formação de professores e a sociedade. Fortaleza: EdUECE, 2015. v. 4. p. 717-729.

. Aprendizagem e desenvolvimento profissional da docência: uma experiência de investigação-formação no curso de Pedagogia. In: FONTOURA, H. A.; TAVARES, M. T. G. (Orgs.). Trabalho docente: experiências formativas e inserção profissional. Niterói: Intertexto, 2013. p. 87-103. (Coleção Educação e Vida Nacional, 8).

MONTEIRO, Filomena M. Arruda; FONTOURA, Helena A.; CANNEN, Ana. Ressignificando práticas de ensino e de formação docente: contribuições de narrativas, diálogos e conferências. Revista de Educação Pública, v. 23, p. 637-654, 2014.

NÓVOA, António. (Org.). Os professores e a sua formação. Lisboa: Dom Quixote, 2008.

. Formação de professores e trabalho pe-

dagógico. Lisboa: Educa, 2002.

. (Org). Vidas de professores. Porto: Porto Editora, 1995.

. (Org.) Os professores e sua formação.

Lisboa: Publicações Dom Quixote, 1992.

. (Org.). Profissão Professor. Porto: Porto
Editora, 1995.

PACHECO, José Augusto; FLORES, Maria Assunção. Formação e avaliação de professores. Porto: Porto Editora, 1999.

SOUZA, Elizeu Clementino de. 0 conhecimento de si: estágio e narrativas de formação de professores. Rio de Janeiro: DP\&A; Salvador: EDUNEB,2006a.

- A arte de contar e trocar experiências: reflexões teórico-metodológicas sobre as histórias de vida em formação. Educação em Questão, v. 25, n. 11, p. 22-39, jan./abr. 2006b.

- O conhecimento de si, as narrativas de formação e o estágio: reflexões teórico-metodológicas sobre uma abordagem experimental de formação inicial de professores. In: ABRAHAO, H. M. B. (Org.). A aventura (auto)biográfica: teoria e empiria. Porto Alegre: EDIPUCRS; Salvador: EDUNEB, 2004. p. 13-27.

ZEICHNER, Kenneth. M. Uma agenda de pesquisa para a formação docente. Revista Brasileira de pesquisa sobre formação docente, Belo Horizonte, v. 1, n. 1, p. 13-40, ago./dez. 2009. Disponível em: <http:// formacaodocente.autenticaeditora.com.br $>$. Acesso em: 12 jun. 2011.

. Formação de professores para a justiça social em tempos de incerteza e desigualdades crescentes. In: DINIZ-PEREIRA, J. E.; ZEICHNER, K. M. (Orgs.). Justiça social - desafio para a formação de professores. Belo Horizonte: Autêntica, 2008. p. 1224.

Recebid o em: 15.09.2016

Aprovado em: 03.11.2016

Filomena Maria de Arruda Monteiro é doutora em Educação pela UFSCar. Professora Associada da Universidade Federal de Mato Grosso. Líder do Grupo de Estudos e Pesquisas em Política e Formação Docente -GEPForDoc. e-mail: filarruda@ hotmail.com.

Av. Fernando Corrêa da Costa, no 2367 - Bairro Boa Esperança. Cuiabá - MT - 78060-900

Helena Amaral da Fontoura é doutora pela Fiocruz. Professora Associada da Universidade do Estado do Rio de Janeiro. Líder do Grupo de Pesquisa Formação de Professores, Processos e Práticas Pedagógicas. e-mail: helenaf@uerj.br.

Rua Dr. Francisco Portela, 1470. Patronato. São Gonçalo, Rio de Janeiro. CEP 24435-005 